\title{
Antiplasmodial Activity Assay of 3-Chloro-4-(4-chlorophenoxy) Aniline Combinations with Artesunate or Chloroquine In Vitro and in a Mouse Model
}

\author{
Martin Wekesa Sifuna $\left(\mathbb{D},{ }^{1}\right.$ Milka Wambui $(D),{ }^{1}$ Joseph Kang'ethe Nganga, \\ Daniel Wainaina Kariuki, ${ }^{1}$ Francis Thuo Kimani, ${ }^{2}$ and Francis Wamakima Muregi ${ }^{3}$ \\ ${ }^{1}$ Biochemistry Department, Jomo Kenyatta University of Agriculture and Technology, P.O. Box 62000, Nairobi, Kenya \\ ${ }^{2}$ Centre for Biotechnology Research and Development, Kenya Medical Research Institute (KEMRI), P.O. Box 54840, \\ Nairobi, Kenya \\ ${ }^{3}$ Department of Biological Sciences, Mount Kenya University, P.O. Box 342, Thika, Kenya
}

Correspondence should be addressed to Milka Wambui; wambuimilka4@gmail.com

Received 22 July 2019; Revised 20 August 2019; Accepted 11 September 2019; Published 17 October 2019

Academic Editor: Xiaoling Miao

Copyright (C) 2019 Martin Wekesa Sifuna et al. This is an open access article distributed under the Creative Commons Attribution License, which permits unrestricted use, distribution, and reproduction in any medium, provided the original work is properly cited.

\begin{abstract}
Malaria is the eighth highest contributor to global disease burden with 212 million cases and 429,000 deaths reported in 2015. There is an urgent need to develop multiple target drug to curb growing resistance by Plasmodia due to use of single target drugs and lack of vaccines. Based on a previous study, 3-chloro-4-(4-chlorophenoxy) aniline (ANI) inhibits Plasmodia enoyl acyl carrier protein reductase. This study aimed at evaluating the antiplasmodial activity of ANI combinations with artesunate (AS) or chloroquine (CQ) against $P$. falciparum in vitro based on the semiautomated microdilution assay and $P$. berghei in vivo based on Peters' 4-day test. Data were analysed by linear regression using version 5.5 of Statistica, 2000. From the results, on the one hand, a combination of $1.1 \mathrm{ng} / \mathrm{ml}$ AS and $3.3 \mu \mathrm{g} / \mathrm{ml}$ of ANI inhibited $50 \%$ growth of $\mathrm{W}_{2}$, while a combination of $0.8 \mathrm{ng} / \mathrm{ml} \mathrm{of} \mathrm{AS} \mathrm{and}$ $2.6 \mu \mathrm{g} / \mathrm{ml}$ of ANI inhibited $50 \%$ growth of $3 \mathrm{D}_{7}$. On the other hand, a combination of $22 \mathrm{ng} / \mathrm{ml} \mathrm{CQ}$ and $3.7 \mu \mathrm{g} / \mathrm{ml}$ of ANI inhibited $50 \%$ growth of $\mathrm{W}_{2}$, while a combination of $4.6 \mathrm{ng} / \mathrm{ml} \mathrm{CQ}$ and $3.1 \mu \mathrm{g} / \mathrm{ml}$ of ANI inhibited $50 \%$ growth of $3 \mathrm{D}_{7}$. In in vivo assays, a combination of $\mathrm{ED}_{50}$ concentrations of $\mathrm{AS}$ and ANI cleared all parasites, while $1 / 2$ and $1 / 4 \mathrm{ED}_{50}$ combinations inhibited $67.0 \%$ and $35.4 \%$ parasite growth, respectively. $\mathrm{ED}_{50}$ combinations of CQ and $\mathrm{ANI}$ inhibited $81.0 \%$ growth of parasites, while $1 / 2$ and $1 / 4$ $\mathrm{ED}_{50}$ combinations inhibited $27.3 \%$ and $10.2 \%$ parasite growth. Assuming a linear relationship between percentage chemosuppression and combination ratios, only $0.88 \mathrm{mg} / \mathrm{kg}$ of AS combined with $1.68 \mathrm{mg} / \mathrm{kg}$ of ANI or $1.78 \mathrm{mg} / \mathrm{kg}$ of CQ with $3.15 \mathrm{mg} /$ $\mathrm{kg}$ of ANI inhibited $50 \%$ parasite growth in vivo. ANI combinations with AS or CQ are thus potential antimalarial drug combinations if their clinical efficacy and safety are ascertained.
\end{abstract}

\section{Introduction}

Malaria remains a major human parasitic disease despite the substantial progress made in the fight against it since 2000 [1]. At the beginning of 2016, malaria was considered to be endemic in only 91 countries and territories, down from 108 in 2000 which was attributed to wide-scale deployment of control interventions which reduced incidence by $41 \%$ and mortality rates by $62 \%$. Updated estimates between 2000 and 2015 indicate that 212 million malaria cases occurred globally in 2015, causing 429000 deaths, especially of expectant mothers and children under 5 years [1].

The plasmodium is transmitted by the female Anopheles mosquito which releases sporozoites into the bloodstream during a blood meal. The parasites evade the host immune system by sequestering inside the red blood cells (RBCs) and the hepatocytes [2]. Usually, the infected RBCs adhere to the walls of blood capillaries evading destruction in the spleen [2]. The sequestration of infected RBCs is highly associated with placental and cerebral malaria [3]. Headache, shivering, 
and joint pain may begin to manifest 8 to 25 days after infection [4]. Draining of stagnant water, indoor residual spraying (IRS), and use of insecticide-treated nets (ITNs) are the most cost-effective parasite vector control measures [5]. ITNs offer over $70 \%$ protection, and between 2000 and 2008, they saved the lives of about 250,000 babies in sub-Saharan Africa, prompting WHO to recommend distribution of affordable ITNs to women in early pregnancy [6].

With challenges in vector control and vaccine development, chemotherapy remains as the mainstay of the malaria control strategy [1]. Quinine was for a long time the drug of choice for management of malaria. Quinine has encountered resistance by the parasite prompting changes to other therapies [7]. Chloroquine (CQ) was a serendipitous drug against Plasmodia used for several decades after quinine, but its use was also halted by development of resistance by the parasite [8]. As a result, artemisinin-based combination therapy (ACT) was adopted as the first-line regimen against falciparum malaria [1]. When the parasite ingests haemoglobin, it releases the heme which activates the artemisinin derivatives such artesunate (AS) generating reactive oxygen radicals that destroy the parasite membranes [9]. AS also inhibits a membrane glutathione s-transferase enzyme that metabolizes the products of lipid peroxidation. Accumulation of lipid peroxides thus kills the parasites [10]. Being a combination of more than one drug, ACT was quite effective against the malaria parasites and AS, one of the drugs on the WHO list of essential medicines, is the most appropriate drug against severe and complicated malaria [11]. The number of course treatments using ACTs had increased from 11 million in 2005 to 337 million by 2014 in an effort to curb growing resistance by plasmodia. Despite continuous effort against malaria, some Plasmodia strains in malaria-endemic regions like Cambodia are developing resistance to the ACTs.

At present, there is still an urgent need to develop new drug combinations early as parasite resistance against present drugs seems to outstrip the rate of drug development which is usually a long process. In a spirited search for a remedy to resistance menace, in silico studies on 3-chloro-4(4-chlorophenoxy) aniline (ANI) have been attempted based on the structural similarity between ANI and triclosan. Triclosan is an antibacterial agent used in tooth paste to inhibit an enoyl-acyl carrier protein reductase enzyme which catalyses the reduction of an enoyl-ACP to an acyl-ACP in the type II (FASII) fatty acid biosynthesis pathway [12]. The FASII pathway is also vital for the development of liver stages of plasmodia [12]. Although the parasite scavenges for fatty acids, destruction of the FASII pathway affects oocyst maturation and sporozoite formation since the pathway supplies specific fatty acids essential for lipid and membrane biogenesis [13]. The FASII pathway is therefore a profound drug target in malaria chemotherapy and hence the proposal to use ANI against plasmodium. Based on this fact, we assayed the antiplasmodial activity of ANI combinations with AS or CQ in vitro against laboratory-adapted $P$. falciparum isolates (CQ sensitive, $3 \mathrm{D}_{7}$; $\mathrm{CQ}$ resistant, $\mathrm{W}_{2}$ ) and in vivo against $P$. berghei. The main objective was to elucidate antiplasmodial activity of ANI and the nature of the drug- drug interactions as either additive, synergistic, or antagonistic and hence the feasibility of using the combinations as an additional ACT to curb malaria.

\section{Materials and Methods}

2.1. Parasite Cultures and Drug Preparation. This study was done in Kenya Medical Research Institute (KEMRI). For in vitro studies, two strains of $P$. falciparum, CQ-sensitive $\left(3 \mathrm{D}_{7}\right)$, and CQ-resistant $\left(\mathrm{W}_{2}\right)$, cryopreserved in the KEMRI malaria laboratory were used, while $P$. berghei ANKA maintained in mice was used for in vivo studies. The drugs were procured from Sigma-Aldrich ${ }^{\circledR}$, prepared, and used freshly. CQ was prepared by dissolving $5 \mathrm{mg}$ in distilled water and then diluted with RPMI to a starting concentration of $1000 \mathrm{ng} / \mathrm{ml}$, while $5 \mathrm{mg}$ of AS and $5 \mathrm{mg}$ ANI was separately dissolved in $0.5 \mathrm{ml}$ of DMSO and diluted with RPMI to starting concentrations of $100 \mathrm{ng} / \mathrm{ml}$ and $1000 \mu \mathrm{g} /$ $\mathrm{ml}$, respectively.

2.2. In Vitro Assays for AS, CQ, and ANI. In vitro parasite sensitivities to individual drugs were assessed as described in [14]. In brief, $50 \mu \mathrm{l}$ of the highest concentration of AS was added to all wells in row B of the 96-well flat-bottomed microtitre plate and then serially diluted two-fold downwards. A $200 \mu \mathrm{l}$ suspension of $P$. falciparum parasitized RBC was added to each well forming a $1 \%$ haematocrit. Column A was the positive and negative control well with no drug. Raw A constituted the control setup. The positive controls had 1\% suspension of infected RBCs in the complete medium, while the negative control wells contained the unparasitized RBC suspension. This protocol was repeated for CQ and ANI. The plates were cultured at $37^{\circ} \mathrm{C}$ under microaerobic environment $\left(91 \% \mathrm{~N}_{2}, 6 \% \mathrm{CO}_{2}\right.$, and $\left.3 \% \mathrm{O}_{2}\right)$ for 48 hours after which $25 \mu \mathrm{l}$ of radiolabelled hypoxanthine was added and incubated for 18 more hours. The plates were then frozen at $-70^{\circ} \mathrm{C}$ overnight and $\mathrm{RBC}$ lysed by thawing to release the parasites which were harvested onto glass fibre filters and dried, and radioactivity was measured by liquid scintillation in counts per minute (cpm). The concentrations causing $50 \%$ inhibition of radioisotope incorporation $\left(\mathrm{IC}_{50}\right)$ which signify presence of life parasites were determined by interpolation after logarithmic transformation of both concentration and the cpm values using the formula:

$$
\mathrm{IC}_{50}=\operatorname{antilog}\left(\log X_{1}+\left[\frac{\left(\log Y_{50}-\log Y_{1}\right)\left(\log X_{2}-\log X_{1}\right)}{\left(\log Y_{2}-\log Y_{1}\right)}\right]\right) \text {, }
$$

where $Y_{50}$ is the midpoint; $X_{1}$ and $X_{2}$ are lower and upper concentrations, respectively; and $Y_{1}$ and $Y_{2}$ are the corresponding cpm values for the data points above and below the cpm midpoints [15].

2.3. In Vitro Assays of Drug Combinations. Based on the individual $\mathrm{IC}_{50}$ obtained in Section 2.2, the drug-drug interaction assays were done as described by Canfield et al. [16]. In brief, fixed-ratio combinations of drug A and drug $\mathrm{B}(9: 1$ to $1: 9)$ were prepared in a manner that the $\mathrm{IC}_{50}$ for 
individual drugs falls in the $4^{\text {th }}$ serial dilution. Each fixedratio combination of desired concentrations was prepared, and $50 \mu \mathrm{l}$ of the starting concentration was added to all wells in row B and then serially diluted two-fold. A $200 \mu \mathrm{l}$ suspension of $P$. falciparum parasitized erythrocytes was added to each well forming a $1 \%$ haematocrit. With wells in column A as controls, the culturing and parasite harvesting and counting were done, as aforementioned in Section 2.2, and the respective inhibitory concentrations were determined as described by Sixsmith. Fractional inhibitory concentrations (FIC) of the drugs were calculated as follows: FIC of drug $\mathrm{A}=\left[\mathrm{IC}_{50}\right.$ of drug $\mathrm{A}$ in combination $/ \mathrm{IC}_{50}$ of drug $\mathrm{A}$ alone $]$ and $\mathrm{FIC}$ of drug $\mathrm{B}=\left[\mathrm{IC}_{50}\right.$ of drug $\mathrm{B}$ in combination/ $\mathrm{IC}_{50}$ of drug $\mathrm{B}$ alone], from which sum $\mathrm{FIC}_{50}$ was derived. A sum of FIC value $<1.0$ denotes synergy, 1.0 denotes additive effect, while a value $>1.0$ denotes antagonism [17].

2.4. Cytotoxicity Assays of Drug Combinations. The present study focused on the toxicity assay for drug combinations with the aim of developing drugs with multiple targets on parasite to reduce resistance development. Therefore, the cytotoxicity assays of ANI combinations with AS or CQ on Vero cell lines were determined using the 3-(4,5-dimethylthiazol-2-yl)-2,5-diphenyltetra-zolium bromide (MTT) cell viability assay [18]. In brief, Vero E6 cells were cultured in minimum essential media supplemented with $10 \%$ foetal bovine serum fortified with $1 \%$ streptozomycine and incubated at $37^{\circ} \mathrm{C}$ and $5 \% \mathrm{CO}_{2}$. The confluent cultures were trypsinized, and concentration was determined by the trypan blue exclusion assay. Of these, $100 \mu$ l containing $2.0 \times 10^{4}$ cells were transferred into each experimental well in the 96 -well culture plate and incubated for $24 \mathrm{hrs}$ at $37^{\circ} \mathrm{C}$ and $5 \% \mathrm{CO}_{2}$ to form about $80-100 \%$ monolayer/confluent. AS $(50 \mu \mathrm{l})$ was added into the first 2 wells to form the highest drug concentration of $1000 \mu \mathrm{g} / \mathrm{ml}$. For the combined drugs, $25 \mu \mathrm{l}$ of AS was added to $25 \mu \mathrm{l}$ of ANI and added into the wells containing $2.0 \times 10^{4}$ cells in $100 \mu \mathrm{l}$ culture media for the highest drug concentration of $1000 \mu \mathrm{g} / \mathrm{ml}$ (consisting $900 \mu \mathrm{g} / \mathrm{ml}$ of the ANI and $100 \mu \mathrm{g} / \mathrm{ml}$ of AS). The protocol was repeated for the CQ-ANI combination using the highest combination drug concentration of $1000 \mu \mathrm{g} / \mathrm{ml}$ (consisting $900 \mu \mathrm{g} / \mathrm{ml}$ of the ANI and $100 \mu \mathrm{g} / \mathrm{ml}$ of CQ). These were then serially diluted downwards and incubated in a humidified incubator at $37^{\circ} \mathrm{C}$. At 48 hours postincubation, an MTT dye was added to the wells and allowed to incubate at $37^{\circ} \mathrm{C}$ for further 3 hours, and the colorimetric reaction stopped by the addition of $100 \mu \mathrm{l}$ of DMSO. The spectrometric absorbance of each well was measured at $450 \mathrm{~nm}$ using scanning multiwell spectrometer (Multiskan EX Lab systems). The data acquired were transferred into the Microsoft excel software (2007) to determine the concentration causing 50\% visible alteration of intact cells $\left(\mathrm{IC}_{50}\right.$ or $\left.\mathrm{CC}_{50}\right)$ as follows: $\%$ cell viability $\left(\mathrm{CC}_{50}\right)=$ $\left[\mathrm{OD}_{\text {sample }} 562-\mathrm{OD}_{620} / \mathrm{OD}_{\text {control562 }}-\mathrm{OD}_{620}\right] \times 100$ [19].

2.5. In Vivo Assays for AS, CQ, and ANI. The four-day suppressive test was adapted for in vivo tests [18] In brief, 65 Swiss albino mice of $20 \pm 2 \mathrm{~g}$ average weight were infected intraperitoneally (ip) with $0.2 \mathrm{ml}$ inoculum containing about $10^{5}$ P. berghei ANKA parasitized RBCs from donor mice on day 0 .

The mice were first randomized into 13 groups of 5 mice each and then into 4 groups for each drug with one negative control group and fed on pellets and watered ad libitum. Three hours postinfection (pi), the drugs are orally administered, as indicated in Table 1 and repeated once daily for 3 days with the negative control mice receiving water containing the same percentage of DMSO. On day 4 pi, percentage chemosuppression was calculated from Giemsastained thin tail-blood smears from mice using the following formula: $[(\mathrm{A}-\mathrm{B}) / \mathrm{A}] \times 100=\%$ chemosuppression, where $\mathrm{A}$ is the mean parasitaemia in the negative control group and $B$ is the mean parasitaemia in test groups. Dosages killing 50\% of parasite $\left(\mathrm{ED}_{50}\right)$ for each drug were determined by linear regression using version 5.5 of Statistica, 2000.

2.6. In Vivo Assays for Drug Combinations. In vivo drug interactions were assessed, as described by Ishih et al. [20]. In brief, 3 fixed-ratio drug doses of ANI combinations with AS or CQ were freshly prepared. Thirty-five Swiss albino mice $(20 \pm 2 \mathrm{~g})$ were infected ip with $0.2 \mathrm{ml}$ blood containing $10^{5}$ P. berghei ANKA parasitized RBC and randomized into 7 groups of 5 mice each. AS and CQ were assigned 3 groups each. Three hours postinfection, one group from the drug groups received a combination of full doses, i.e., the individual $\mathrm{ED}_{50}$ quantities of each drug, the other group half the individual $\mathrm{ED}_{50}$ quantities of each drug, and the last group received a quarter of the $\mathrm{ED}_{50}$ quantities of each drug. The negative control mice received water containing the same percentage of DMSO. Drugs were orally administered once daily for 3 days. On day 4 pi, percentage chemosuppression was calculated from Giemsa-stained thin tail-blood smears and their $\mathrm{ED}_{50}$ was determined by linear regression using version 5.5 of Statistica, 2000. Student's $t$-test was used to determine statistical significance at 95\% confidence level.

2.7. Data Analysis. The top-count microplate scintillation and luminescence counter provided the in vitro results as cpm per minute expressed as percentage of the controls. $\mathrm{IC}_{50}$ was estimated by linear interpolation [21]. The data were then analysed in Microsoft Excel, and $\mathrm{IC}_{50}$ concentrations of the drugs were obtained by logarithm-transformed concentration values [22]. The $\mathrm{IC}_{50}$ and standard deviation values were calculated from duplicate values for all drugs tested. For in vivo assays, percentage parasitaemia was recorded in Excel (Microsoft) and expressed as the mean \pm standard error of mean. $\mathrm{ED}_{50}$ was determined by linear regression using version 5.5 of Statistica 2000. Statistical analysis of the data was done using Student's $t$-test with a significance level set at $p<0.05$.

\section{Results}

3.1. In Vitro $I_{50}$ Values for AS, CQ, and ANI and Their Combinations. Table 2 illustrates the $\mathrm{IC}_{50}$ values of $\mathrm{AS}, \mathrm{CQ}$, and ANI and their respective combinations for the two 
TABLE 1: In vivo individual drug assays.

\begin{tabular}{lcccc}
\hline \multirow{2}{*}{ Drug dosages } & \multicolumn{4}{c}{ Animal test population groups } \\
& I & II & III & IV \\
\hline AS (mg/kg/day) & 5 & 2.5 & 1.25 & 0.65 \\
CQ (mg/kg/day) & 5 & 2.5 & 1.25 & 0.65 \\
ANI (mg/kg/day) & 10 & 5 & 2.5 & 1.25 \\
Control & - & - & - & - \\
\hline
\end{tabular}

The starting concentrations were chosen based on the existing literature except for the novel drug ANI that was on trial.

TABle 2: In vitro $\mathrm{IC}_{50}$ values of $\mathrm{AS}, \mathrm{CQ}$, and $\mathrm{ANI}$ against Plasmodium isolates.

\begin{tabular}{lcc}
\hline \multirow{2}{*}{ Drug } & CQ sensitive $\left(3 \mathrm{D}_{7}\right)$ & CQ resistant $\left(\mathrm{W}_{2}\right)$ \\
& $\mathrm{IC}_{50} \pm \mathrm{SD}$ & $\mathrm{IC}_{50} \pm \mathrm{SD}$ \\
\hline ANI & $7.12 \pm 0.17 \mu \mathrm{g} / \mathrm{ml}$ & $8.75 \pm 0.3 \mu \mathrm{g} / \mathrm{ml}$ \\
$\mathrm{CQ}$ & $10.9 \pm 1.1 \mathrm{ng} / \mathrm{ml}$ & $48 \pm 0.07 \mathrm{ng} / \mathrm{ml}$ \\
$\mathrm{AS}$ & $1.6 \pm 0.05 \mathrm{ng} / \mathrm{ml}$ & $2.4 \pm 0.1 \mathrm{ng} / \mathrm{ml}$ \\
\hline
\end{tabular}

ANI had lower in vitro antiplasmodial activity compared to AS and CQ with its values in $\mu \mathrm{g} / \mathrm{ml}$.

parasite strains, $3 \mathrm{D}_{7}$ and $\mathrm{W}_{2}$. The parasite was less responsive to the ANI as compared to CQ and AS which was the most active against the Plasmodia.

In combinations, only $0.8 \mathrm{ng} / \mathrm{ml}$ of AS combined with $2.6 \mu \mathrm{g} / \mathrm{ml}$ of ANI as opposed to $1.6 \mathrm{ng} / \mathrm{ml}$ of AS and $7.12 \mu \mathrm{g} /$ $\mathrm{ml}$ of ANI individually administered attained $50 \% 3 \mathrm{D}_{7}$ growth inhibition. Similarly, only $1.1 \mathrm{ng} / \mathrm{ml}$ of AS combined with $3.3 \mu \mathrm{g} / \mathrm{ml}$ of ANI inhibited $50 \%$ growth of $\mathrm{W}_{2}$ as compared to $2.4 \mathrm{ng} / \mathrm{ml}$ of AS and $8.75 \mu \mathrm{g} / \mathrm{ml}$ of ANI individually required similar inhibition. At all combinations of ANI with either AS or CQ, the drug interactions demonstrated synergy with sum FIC values $<1$, as shown in Table 3 .

3.2. Cytotoxicity Assays for Drug Combinations. The selective index of the combination drugs was determined by finding the ratio between $\mathrm{IC}_{50}$ of the drug against Vero E6 cells and against parasites. The $50 \%$ cytotoxic level of ANI combination with AS was $35.43 \mu \mathrm{g} / \mathrm{ml}$ with a selective index of 13.6 while that of ANI combination with CQ was $41.13 \mu \mathrm{g} / \mathrm{ml}$ with a selective index of 13.3 , as shown in Table 4 .

\subsection{In Vivo Inhibitory Properties of AS, CQ, and ANI and Their} Combinations. Of the three drugs tested in vivo, AS was the most active drug with an $\mathrm{ED}_{50}$ of $2.2 \mathrm{mg} / \mathrm{kg}$ body weight, while CQ had an $\mathrm{ED}_{50}$ of $2.38 \mathrm{mg} / \mathrm{kg}$ body weight. The ANI had an $\mathrm{ED}_{50}$ of $4.18 \mathrm{mg} / \mathrm{kg}$ and $\mathrm{ED}_{90}$ of $9.1 \mathrm{mg} / \mathrm{kg}$ body weight, as shown in Table 5.

The ANI combination with AS was more synergistic both at $\mathrm{ED}_{50}$ and lower combination values, while $\mathrm{ANI}$ combination with CQ showed trends towards synergy at higher combination concentrations alone. $\mathrm{ED}_{50}$ combination of $\mathrm{AS}$ and $\mathrm{ANI}$ was able to clear the parasites, while half $\mathrm{ED}_{50}$ combinations still produced an inhibition higher than 50\%, a show of synergy. On the contrary, $\mathrm{ED}_{50}$ combination of $\mathrm{CQ}$ and ANI had $81 \%$ growth inhibition on the parasite. The drug combinations needed to attain $50 \%$ parasite growth suppression was $0.88 \mathrm{mg} /$ $\mathrm{kg}$ of AS combined with $1.68 \mathrm{mg} / \mathrm{kg}$ of ANI or $1.78 \mathrm{mg} / \mathrm{kg}$ of CQ combined with $3.15 \mathrm{mg} / \mathrm{kg}$ of ANI.

\section{Discussion}

Evolution of drug-resistant parasites to antimalarial drugs including ACTs is a major hindrance to malaria control, and therefore, effective management of malaria will only be realized through development of new therapies [22]. Constant monitoring of developing resistance and development of new therapies, needed approximately every ten years, is of utmost importance so as to keep malaria control efficacious [23]. Coformulation of antimalarial drugs with multiple targets optimizes efficacy due to synergistic effects of one drug on the other, and delaying the development of resistance is the current strategy in development of malaria therapies. Drug combination therapy also reduces chances of toxicity, increasing safety and drug tolerability, as well as increasing the efficacy of member drugs [24].

Of the three drugs under the in vitro study, AS was the most active with $\mathrm{IC}_{50}$ values of $1.6 \mathrm{ng} / \mathrm{ml}$ against $3 \mathrm{D}_{7}$ and $2.4 \mathrm{ng} / \mathrm{ml}$ against $\mathrm{W}_{2}$, while CQ had an $\mathrm{IC}_{50}$ value of $10.9 \mathrm{ng} /$ $\mathrm{ml}$ against $3 \mathrm{D}_{7}$ and $48 \mathrm{ng} / \mathrm{ml}$ against $\mathrm{W}_{2}$. The $\mathrm{ANI}$ was less effective in vitro as compared to either $\mathrm{AS}$ or $\mathrm{CQ}$ with $\mathrm{IC}_{50}$ values of $7.12 \mu \mathrm{g} / \mathrm{ml}$ against $3 \mathrm{D}_{7}$ and $8.75 \mu \mathrm{g} / \mathrm{ml}$ against $\mathrm{W}_{2}$ (Table 2). ANI's different mechanisms of action make it an ideal partner drug to the present antimalarial drugs. Indeed, a combination of ANI with AS or CQ exhibited increased parasite clearance (Table 3 ), as compared to administration of individual administration drugs. An AS combination with ANI was more potent both in vitro and in vivo cases with only $1.1 \mathrm{ng} / \mathrm{ml}$ of AS $\left(\mathrm{IC}_{50} ; 2.4 \mathrm{ng} / \mathrm{ml}\right)$, and $3.3 \mu \mathrm{g} / \mathrm{ml}$ of ANI $\left(\mathrm{IC}_{50} ; 8.75 \mu \mathrm{g} / \mathrm{ml}\right)$ was needed to attain $50 \%$ inhibition of $P$. falciparum, $\mathrm{W}_{2}$ with a sum FIC of 0.82 on $\mathrm{W}_{2}$, and 0.86 on $3 \mathrm{D}_{7}$ (Table 3). Similar synergistic effects were also demonstrated between the CQ combination with ANI where only $22 \mathrm{ng} / \mathrm{ml}$ of CQ $\left(\mathrm{IC}_{50} ; 48 \mathrm{ng} / \mathrm{ml}\right)$ and $3.7 \mu \mathrm{g} / \mathrm{ml}$ of ANI $\left(\mathrm{IC}_{50} ; 8.75 \mu \mathrm{g} / \mathrm{ml}\right.$ ) were required to produce $50 \%$ inhibition of growth of $\mathrm{W}_{2}$, and only $4.6 \mathrm{ng} / \mathrm{ml}$ of CQ combined with $3.1 \mu \mathrm{g} / \mathrm{ml}$ of ANI produced $50 \%$ inhibition of growth of $3 \mathrm{D}_{7}$ with a sum FIC of 0.87 on $\mathrm{W}_{2}$ and 0.85 on $3 \mathrm{D}_{7}$ (Table 3 ). These findings thus point at the potential of the ANI combinations with AS or CQ as a possible remedy to the growing parasite resistance to the present antimalarial therapies.

Acute cytotoxicity and toxicity assays are paramount in predicting the possible risks of the formulated drugs in humans exposed to fatal doses, enabling anticipation of the nature of an acute response by body systems [25]. The $\mathrm{IC}_{50}$ of AS was $62.32 \mathrm{ng} / \mathrm{ml}$, while its combination with ANI had an $\mathrm{IC}_{50}$ of $35.43 \mu \mathrm{g} / \mathrm{ml}$ with a selective index of 13.6. CQ combination with ANI had an $\mathrm{IC}_{50}$ of $41.13 \mu \mathrm{g} / \mathrm{ml}$ with a selective index of 13.3. With the selective index of over 10 times the therapeutic levels (Table 4), these drug combinations are safe, considering the low amounts of drug combinations that course a remarkable parasitaemia suppression.

At $5 \mathrm{mg} / \mathrm{kg}$ of $\mathrm{ANI}, \mathrm{AS}$, and CQ in individual in vivo studies, ANI demonstrated a remarkable parasite 
TABLE 3: In vitro $\mathrm{IC}_{50}$ values for $\mathrm{ANI}$ in combination with either AS or CQ against Plasmodium isolates.

\begin{tabular}{lccccc}
\hline Combination & Strain & Combination quantities & FIC; AS or CQ & FIC; ANI & Sum FIC \\
\hline \multirow{2}{*}{ AS/ANI } & $3 \mathrm{D}_{7}$ & $0.8 \mathrm{ng} / \mathrm{ml} \mathrm{AS}+2.6 \mu \mathrm{g} / \mathrm{ml} \mathrm{ANI}$ & 0.5 & 0.36 & 0.86 \\
& $\mathrm{~W}_{2}$ & $1.1 \mathrm{ng} / \mathrm{ml} \mathrm{AS}+3.3 \mu \mathrm{g} / \mathrm{ml}$ ANI & 0.45 & 0.82 \\
CQ/ANI & $3 \mathrm{D}_{7}$ & $4.6 \mathrm{ng} / \mathrm{ml} \mathrm{CQ}+3.1 \mu \mathrm{g} / \mathrm{ml} \mathrm{ANI}$ & 0.42 & 0.43 & 0.85 \\
& $\mathrm{~W}_{2}$ & $22 \mathrm{ng} / \mathrm{ml} \mathrm{CQ}+3.7 \mu \mathrm{g} / \mathrm{ml} \mathrm{ANI}$ & 0.45 & 0.42 & 0.87 \\
\hline
\end{tabular}

The drug combination concentrations were based on concentrations inhibiting $50 \%$ growth of parasite. With sum FIC values $<1$, these combinations are synergistic against the parasite.

TABLE 4: $\mathrm{IC}_{50}$ and selective index values for drug combinations against Vero $\mathrm{E} 6$ and $3 \mathrm{D}_{7}$ cells.

\begin{tabular}{lccc}
\hline \multirow{2}{*}{ Drug } & & $\mathrm{IC}_{50} \mu \mathrm{g} / \mathrm{ml}$ & \\
& Vero E6 & $3 D_{7}$ & SI \\
\hline AS-ANI & 35.43 & 2.6 & 13.6 \\
CQ-ANI & 41.13 & 3.1 & 13.3 \\
\hline
\end{tabular}

Selective index for safety analysis: selective indices were over 10 times the $\mathrm{ED}_{50}$ values of individual drugs thus safe.

TABle 5: Antiplasmodial activity of AS, CQ, and ANI on day 4 pi against $P$. berghei ANKA.

\begin{tabular}{lcc}
\hline Drug & \multicolumn{2}{c}{$\begin{array}{c}\text { Inhibitory concentrations } \\
(\mathrm{mg} / \mathrm{kg} / \text { day) on day } 4 \text { pi }\end{array}$} \\
& $\mathrm{ED}_{50}$ & $\mathrm{ED}_{90}$ \\
\hline AS & 2.22 & 4.2 \\
$\mathrm{CQ}$ & 2.38 & 4.75 \\
ANI & 4.18 & 9.1 \\
\hline
\end{tabular}

The effective doses inhibit growth of parasites by $50 \%\left(\mathrm{ED}_{50}\right)$. AS is two-fold more effective than ANI.

chemosuppression capacity (75.3\%) relative to the controls $(p<0.05)$, with an $\mathrm{ED}_{50}$ of $4.18 \mathrm{mg} / \mathrm{kg}$ body weight. This suppression was comparable with that of AS (98.7\%) with an $\mathrm{ED}_{50}$ of $2.2 \mathrm{mg} / \mathrm{kg}$ body weight and CQ (90.5\%) with an $\mathrm{ED}_{50}$ of $4.18 \mathrm{mg} / \mathrm{kg}$ body weight (Table 5 ). These drug combinations showed better inhibitory activity against $P$. berghei in vivo as was with $P$. falciparum in vitro with parasite suppression by the two drug combinations statistically significant $(p<0.05)$. A combination of AS and ANI provided better parasite inhibition both at $\mathrm{ED}_{50}$ drug combinations as well as at lower combination dosages. An $\mathrm{ED}_{50}$ drug combination between AS and ANI was able to clear the entire parasite, while a combination of half their respective $\mathrm{ED}_{50}$ values inhibited $67.0 \%$ parasite growth which was higher than the $50 \%$ inhibitory effect produced by the respective drugs administered individually. A quarter $\mathrm{ED}_{50}$ combination had a $35.4 \%$ growth inhibition. A $2.4 \mathrm{mg} /$ $\mathrm{kg}$ body weight dose of CQ and $4.2 \mathrm{mg} / \mathrm{kg}$ body weight dose of ANI produced a 50\% growth inhibition of $P$. berghei in mice when individually administered. However, a combination of these drugs' $\mathrm{ED}_{50}$ values had a much higher growth inhibition of $81 \%$. A combination of half and quarter of their respective $\mathrm{ED}_{50}$ values cleared $27.2 \%$ and $10.2 \%$ of the parasites, respectively. This shows a synergistic effect between the activity of CQ and ANI though at high levels of their respective $\mathrm{ED}_{50}$ values only a much lower combination less than their respective $\mathrm{ED}_{50}$ produced a much lower inhibitory effect.
The drug combination ratios needed to attain 50\% parasite chemosuppression was $0.88 \mathrm{mg} / \mathrm{kg}$ of AS combined with $1.68 \mathrm{mg} / \mathrm{kg}$ of ANI or $1.78 \mathrm{mg} / \mathrm{kg}$ of CQ combined with $3.15 \mathrm{mg} / \mathrm{kg}$ of ANI assuming there exists a linear relationship between the percentage chemosuppression and the combination ratios. This shows that when used in combination, less of the drugs is needed to attain the same therapeutic effect. This reduction in the concentrations used in combinations is due to the differences in the drug targets on the parasite metabolic pathways as elucidated in Introduction. The capacity of the combination drug agent to target different functional molecules within the parasites retards its chances of developing resistance as well as reduces chances of toxicity to the host animal and production costs [25].

In conformity to the less-drug-usage-higher-therapeutic-effect-and-low-toxicity principle above, observation of the mice posttreatment showed that there were high survival rates when combination drugs were employed compared to when they were administered individually. Remarkable parasitaemia suppression by the drugs in combination relative to the effect of the drugs individually administered was a classic example of drug synergy.

\section{Conclusion}

In principle, this study has demonstrated that ANI has antiplasmodial activity against 4 -aminoquinoline-sensitive and -resistant $P$. falciparum lines. ANI combinations with either artesunate or chloroquine are more effective against Plasmodia with increased parasite clearance due to dual targets against the parasites. Potent antimalarial activity of ANI combinations with either AS or CQ implies that the combinations can be explored for future development of affordable but more effective antimalarial drugs that will mitigate growing resistance if their clinical efficacies can be demonstrated. The study recommends in vivo assays of the drug combinations in primate models towards clinical trials with human subjects.

\section{Abbreviations}

AS: $\quad$ Artesunate

CQ: $\quad$ Chloroquine

ANI: 3-Chloro-4-(4-chlorophenoxy) aniline

IC50: Inhibitory concentration that reduces parasite growth by $50 \%$

ED50: Effective dose that reduces parasitaemia by $50 \%$

FIC: Fractional inhibitory concentration

WHO: World Health Organization 
IRS: Indoor residual spraying

ITNs: Insecticide-treated nets

ACT: Artemisinin-based combination therapy

ACP: Acyl carrier protein

FASII: Fatty acid biosynthesis type II

KEMRI: Kenya Medical Research Institute

RBCs: Red blood cells

pi: $\quad$ Postinfection

ip: Intraperitoneally

OD: Optical density

CC50: Concentration causing 50\% visible alteration of intact cells

CPM: $\quad$ Counts per minute.

\section{Data Availability}

The data used to support the findings of this study are included within the article. Any additional data are available from the corresponding author upon request.

\section{Ethical Approval}

The permission was granted by the Animal Care and Use Committee (ACUC), KEMRI, and all animal experiments conducted after the study were approved by Mount Kenya University Ethics Review Committee (MKU-ERC), Approval No. MKU/ERC/0327. MKU-ERC is accredited by the National Commission for Science, Technology and Innovation (NACOSTI). All efforts were made to minimize animal suffering and were euthanized using $150 \mathrm{mg} / \mathrm{kg}$ body weight sodium pentobarbital solution injected intraperitoneally after their intended use. Red blood cells and human sera for culturing $P$. falciparum were obtained upon signed acceptance of informed consent terms and conditions by the blood donors. Any radioactive waste generated was referred to the KEMRI biosafety occupational health safety and environment office for disposal.

\section{Conflicts of Interest}

The authors declare that they have no conflicts of interest.

\section{Acknowledgments}

This work was supported by a research grant from JKUATResearch Production and Extension awarded to J. K Nganga in 2012. The authors thank KEMRI Malaria Laboratory and the Animal facility staff led by Mr. Lucas Ogutu for availing us with parasites, mice, and their support in animal handling.

\section{References}

[1] World Health Organization, World Malaria Report 2014, WHO, Geneva, Switzerland, 2014.

[2] L. Tilley, M. W. A. Dixon, and K. Kirk, "The Plasmodium falciparum-infected red blood cell," The International Journal of Biochemistry \& Cell Biology, vol. 43, no. 6, pp. 839-842, 2011.
[3] P. F. Mens, E. C. Bojtor, and H. D. F. H. Schallig, "Molecular interactions in the placenta during malaria infection," $E u$ ropean Journal of Obstetrics \& Gynecology and Reproductive Biology, vol. 152, no. 2, pp. 126-132, 2010.

[4] A. Bartoloni and L. Zammarchi, "Clinical aspects of uncomplicated and severe malaria," Mediterranean Journal of Hematology and Infectious Diseases, vol. 4, no. 1, Article ID e2012026, 2012.

[5] H. Caraballo and K. King, "Emergency department management of mosquito-borne illness: malaria, dengue, and West Nile virus," Emergency Medicine Practice, vol. 16, no. 5, pp. 1-23, 2014.

[6] K. Raghavendra, T. K. Barik, B. P. N. Reddy, P. Sharma, and A. P. Dash, "Malaria vector control: from past to future," Parasitology Research, vol. 108, no. 4, pp. 757-779, 2011.

[7] J. Achan, A. O Talisuna, A. Erhart et al., "Quinine, an old antimalarial drug in a modern world: role in the treatment of malaria," Malaria Journal, vol. 10, no. 1, p. 144, 2011.

[8] K. Krafts, E. Hempelmann, and A. Skórska-Stania, "From methylene blue to chloroquine: a brief review of the development of an antimalarial therapy," Parasitology Research, vol. 111, no. 1, pp. 1-6, 2012.

[9] N. Klonis, M. P. Crespo-Ortiz, I. Bottova et al., “Artemisinin activity against Plasmodium falciparum requires hemoglobin uptake and digestion," Proceedings of the National Academy of Sciences, vol. 108, no. 28, pp. 11405-11410, 2011.

[10] A. M. Lisewski, J. P. Quiros, C. L. Ng et al., "Supergenomic network compression and the discovery of EXP1 as a glutathione transferase inhibited by artesunate," Cell, vol. 158, no. 4, pp. 916-928, 2014.

[11] D. Sinclair, S. Donegan, R. Isba, and D. G. Lalloo, "Artesunate versus quinine for treating severe malaria," Cochrane Database of Systematic Reviews, no. 6, 2012.

[12] M. J. Shears, C. Y. Botté, and G. I. McFadden, "Fatty acid metabolism in the Plasmodium apicoplast: drugs, doubts and knockouts," Molecular and Biochemical Parasitology, vol. 199, no. 1-2, pp. 34-50, 2015.

[13] B. C. L. van Schaijk, T. R. S. Kumar, M. W. Vos et al., “Type II fatty acid biosynthesis is essential for Plasmodium falciparum sporozoite development in the midgut of Anopheles mosquitoes," Eukaryotic Cell, vol. 13, no. 5, pp. 550-559, 2014.

[14] R. E. Desjardins, C. J. Canfield, J. D. Haynes, and J. D. Chulay, "Quantitative assessment of antimalarial activity in vitro by a semiautomated microdilution technique," Antimicrobial Agents and Chemotherapy, vol. 16, no. 6, pp. 710-718, 1979.

[15] D. G. Sixsmith, H. C. Spencer, J. D. Chulay, and W. M. Watkins, "In vitro antimalarial activity of tetrahydrofolate dehydrogenase inhibitors," The American Journal of Tropical Medicine and Hygiene, vol. 33, no. 5, pp. 772-776, 1984.

[16] C. J. Canfield, M. Pudney, and W. E. Gutteridge, "Interactions of atovaquone with other antimalarial drugs against Plasmodium falciparum in vitro," Experimental Parasitology, vol. 80, no. 3, pp. 373-381, 1995.

[17] M. C. Berenbaum, "A method for testing for synergy with any number of agents," Journal of Infectious Diseases, vol. 137, no. 2, pp. 122-130, 1978.

[18] W. Peters, J. H. Portus, and B. L. Robinson, "The chemotherapy of rodent malaria, XXII," Annals of Tropical Medicine \& Parasitology, vol. 69, no. 2, pp. 155-171, 1975.

[19] T. Mosmann, "Rapid colorimetric assay for cellular growth and survival: application to proliferation and cytotoxicity assays," Journal of Immunological Methods, vol. 65, no. 1-2, pp. 55-63, 1983. 
[20] A. Ishih, T. Suzuki, T. Hasegawa, S. Kachi, H.-H. Wang, and M. Terada, "In vivo evaluation of combination effects of chloroquine with cepharanthin or minocycline hydrochloride against blood-induced chloroquine-resistant plasmodium berghei nk 65 infections," Tropical Medicine and Health, vol. 32, no. 1, pp. 15-19, 2004.

[21] W. Huber and J. C. Koella, "A comparison of three methods of estimating $\mathrm{EC}_{50}$ in studies of drug resistance of malaria parasites," Acta Tropica, vol. 55, no. 4, pp. 257-261, 1993.

[22] W. R. Gimode, D. M. Kiboi, F. T. Kimani, H. N. Wamakima, M. W. Burugu, and F. W. Muregi, "Fitness cost of resistance for lumefantrine and piperaquine-resistant Plasmodium berghei in a mouse model," Malaria Journal, vol. 14, no. 1, p. 38, 2015.

[23] T. J. Egan and D. Kuter, "Dual-functioning antimalarials that inhibit the chloroquine-resistance transporter," Future Microbiology, vol. 8, no. 4, pp. 475-489, 2013.

[24] D. Agarwal, M. Sharma, S. K. Dixit et al., "In vitro synergistic effect of fluoroquinolone analogues in combination with artemisinin against Plasmodium falciparum; their antiplasmodial action in rodent malaria model," Malaria Journal, vol. 14, no. 1, p. 48, 2015.

[25] S. O. Aniagu, F. C. Nwinyi, D. D. Akumka et al., "Toxicity studies in rats fed nature cure bitters," African Journal of Biotechnology, vol. 4, no. 1, pp. 72-78, 2005. 


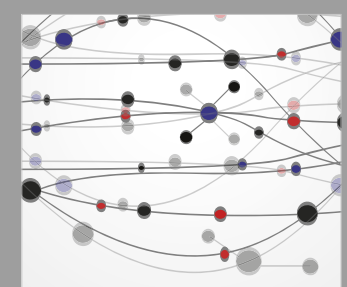

The Scientific World Journal
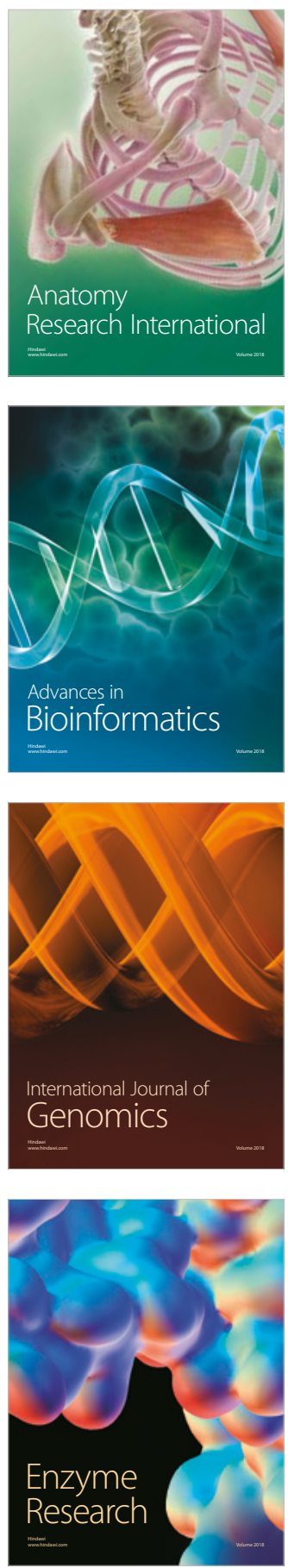
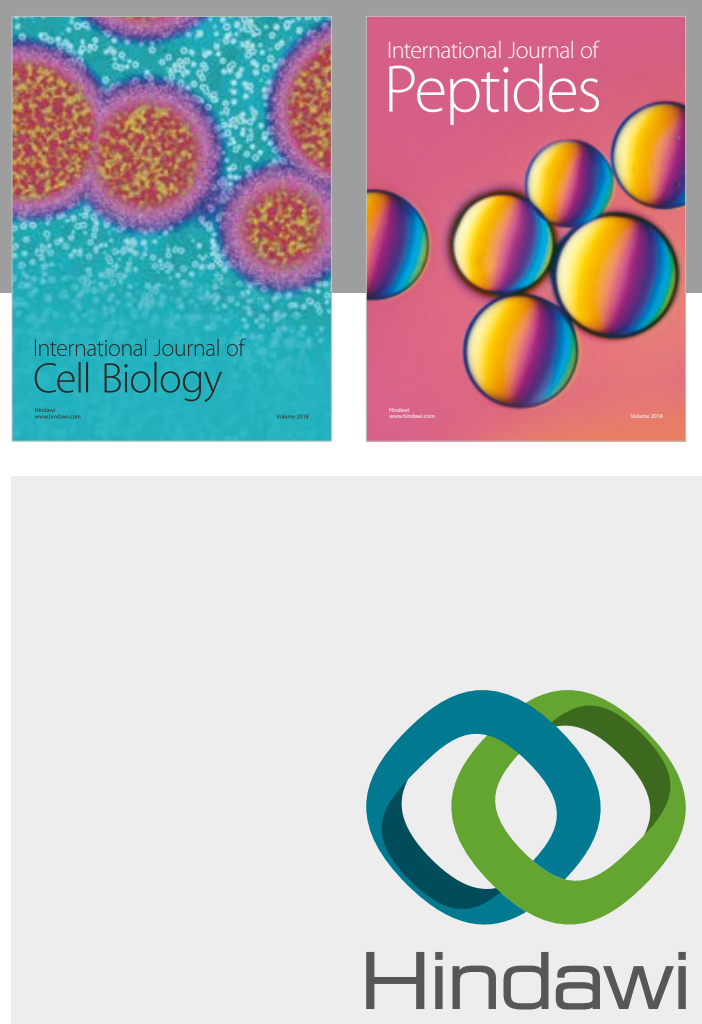

Submit your manuscripts at

www.hindawi.com
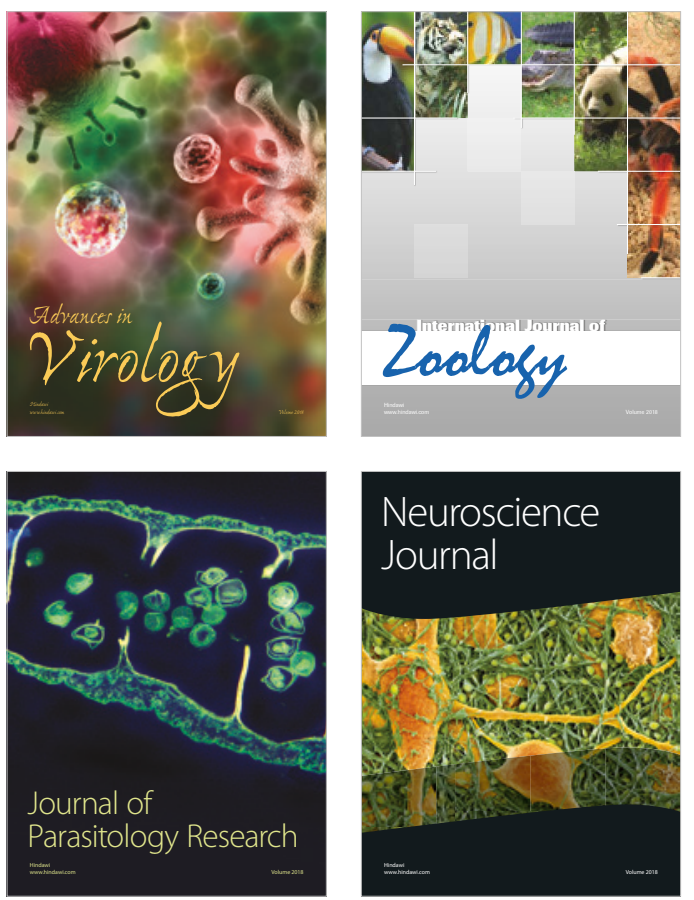
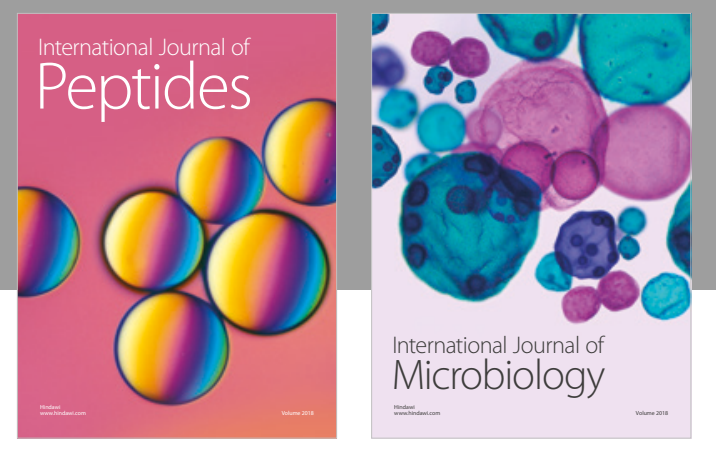

nternational Journal of Microbiology
Journal of
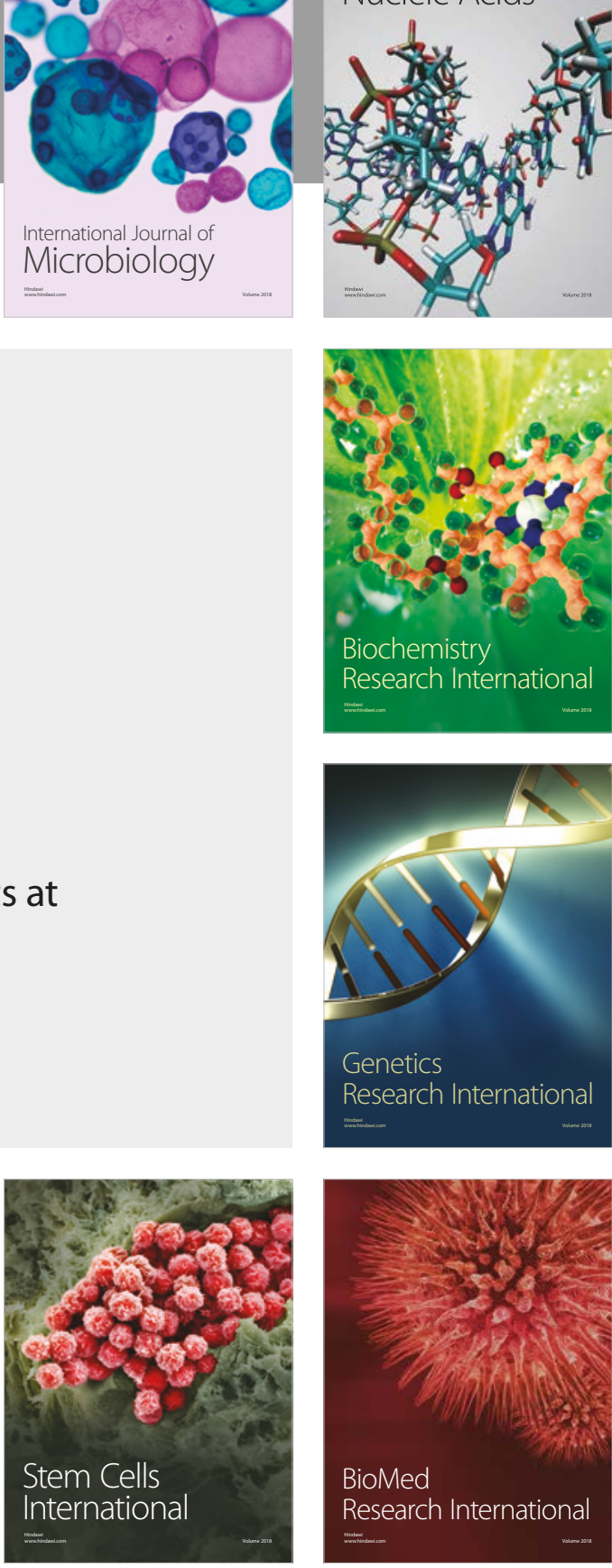
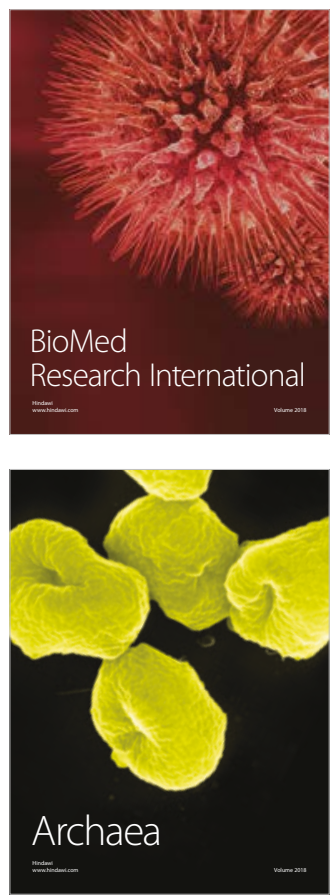